Article

\title{
The role of parents and related factors on adolescent computer use
}

\author{
Jennifer A. Epstein \\ Weill Cornell Medical College, Department of Public Health, Division of Prevention and Health \\ Behavior, New York, NY, USA
}

Significance for public health

The study is significant to public health in that it contributes information about which details are critical for a public health campaign aimed at parents to decrease their children's time spent on recreational computer use. Clearly, this study along with past research of other behaviors affecting adolescent public health shows the importance of greater reported parental monitoring in this case on decreased adolescent recreational computer use. Furthermore, parents can model their own computer behavior and ensure that their children do not start using computers at too young an age. Parents can also model and discuss ways their children could best use the Internet. Through parental monitoring and discussion with their children, parents should be able to deal appropriately with various Internet activities. Moreover, greater recreational computer use has been associated with alcohol, smoking and other drug use, as well as a sedentary behavior all affecting the public health of adolescents.

\section{Abstract}

Background. Research suggested the importance of parents on their adolescents' computer activity. Spending too much time on the computer for recreational purposes in particular has been found to be related to areas of public health concern in children/adolescents, including obesity and substance use.

Design and Methods. The goal of the research was to determine the association between recreational computer use and potentially linked factors (parental monitoring, social influences to use computers including parents, age of first computer use, self-control, and particular internet activities). Participants (aged 13-17 years and residing in the United States) were recruited via the Internet to complete an anonymous survey online using a survey tool. The target sample of 200 participants who completed the survey was achieved. The sample's average age was 16 and was $63 \%$ girls.

Results. A set of regressions with recreational computer use as dependent variables were run.

Conclusions. Less parental monitoring, younger age at first computer use, listening or downloading music from the internet more frequently, using the internet for educational purposes less frequently, and parent's use of the computer for pleasure were related to spending a greater percentage of time on non-school computer use. These findings suggest the importance of parental monitoring and parental computer use on their children's own computer use, and the influence of some internet activities on adolescent computer use. Finally, programs aimed at parents to help them increase the age when their children start using computers and learn how to place limits on recreational computer use are needed.

\section{Introduction}

Young people are fleeing a world once dominated by television to one dominated by computers and the Internet. ${ }^{1}$ In the past, television was viewed as a passive activity taking time away from adolescents to engage in other activities. Now, although teens still watch television, computer use and Internet use particularly for non-school use or recreational use are on the rise. Some believe that excessive computer use particularly related to game and other recreational use may represent a form of addiction. ${ }^{2,3}$ In a literature review, social networking sites seemed to be more addictive for those engaging in social searching and having certain personality traits. ${ }^{4}$ Research has found that drinking alcohol was associated with non-school computer use but not computer use related to school among adolescents. ${ }^{5}$ Another survey indicated that teenagers using social networking sites were at increased risk of smoking, drinking alcohol and drug use. ${ }^{6}$ The potentially addictive quality for those engaged in computer activities deserves further exploration. Other health threats from too much recreational computer use pertain to the sedentary aspect of this activity.

Time spent on the computer and Internet needs to be examined more closely as a public health issue. Specifically, an understanding of what factors play a role in protecting against or promoting greater time on computers for non-school/recreational purposes would seem warranted as scant literature is available in this area. The role of parents, friends, characteristics like self-control, and Internet activity are ripe areas to explore their relationship with adolescent computer use especially excluding time spent on school work. By understanding these factors better, it will be possible to develop guidance for parents about their children's computer use.

Parents typically play a key role in their children's lives. For nearly 30 years, the strongest results coming from studies connecting adolescent behaviors (e.g., delinquency, drinking alcohol, drug use) with parenting have been for parental monitoring. ${ }^{7}$ One description has been offered by Biglan: ${ }^{8}$ parents who know what their children are doing are able to detect when the child is drifting into activities that might pose a risk. Similarly, it is possible for parents to know what their children are doing on computers/online and set appropriate rules to decrease access or monitor access during non-school use. There are many reasons why parents would wish to limit activity including: avoiding their children staying up late using computers resulting in lack of sleep, too much time recreating on the computer and not enough time spent on school work, and concerns about their children encountering strangers or other people who make their children uncomfortable on the Internet (e.g., cyberbullying). As prohibiting adolescents from using the web is not considered realistic, parental controls (a type of parental monitoring for the computer and Internet) allow parents to set time limits and keep them within certain websites. ${ }^{9}$

Self-control is the idea of effortful regulation of the self by the self; self-controlled individuals are more adept than their impulsive counterparts at regulating their behavioral, emotional, and attentional 
impulses to achieve long-term goals. ${ }^{10}$ Having self-control over computer use excluding school work could be beneficial. Such individuals may not spend too much time on the short-term payoffs of computer games and Internet activities (computer use excluding school work). Interestingly, SelfControl is the name of an open source tool for Apple's Mac OS to block oneself from using certain Internet sites or email. Its intended audience is adults yet this software solution recognizes that people need self-control to navigate today's technological computer world. Today's teen has a multitude of activities to engage in over the Internet, including playing online games, playing violent games, using chat rooms, listening to or downloading music, and educational purposes. Some of these examples may pose some risk to adolescents. Playing violent games could desensitize them to violence. ${ }^{11}$ Using chat rooms could expose teens to strangers. ${ }^{12}$ Social learning theory ${ }^{13}$ posits that people learn behaviors from others through a process of observing, modeling, imitation and reinforcement. Therefore, when adolescents observe their friends and/or parents using computers for pleasure it would be expected that the adolescents would also use computers for similar reasons. Friends and parents have influenced adolescents through their behavior and/or attitudes to use cigarettes, alcohol, other drugs based on review of the literature. ${ }^{14}$ This study seeks to inform society about how to best engage our nation's youth in computer activities. In particular, what role do parents have in setting limits (e.g., time limits, instructions to take breaks for their children for computer activities as with other responsibilities parents face (e.g., setting bedtimes and curfews)? By examining the relationship between parental monitoring related to non-school computer use measured as a percentage of computer time, it will be possible to determine the effectiveness of these strategies on their children. The model will also test the roles of self-control, activities on the Internet, friends' and parents' use of computers for pleasure in terms of their association with amount of time spent on the computer excluding schoolwork.

\section{Materials and Methods}

Adolescents residing in the United States responded to recruitment efforts for an anonymous survey via the Internet (e.g., web sites with lists of psychology studies, of blogs listing studies) and word of mouth from the Internet recruitment (teachers, friends) during the 2009-2010 academic year. This study and recruitment effort, which was approved by the Institutional Review Board (IRB), was conducted online about computer use and health on a popular online survey tool. Moreover, the study complied with the Helsinki Declaration of 1975 . The IRB required that data must be anonymous due to the adolescent age group.

The recruitment efforts resemble those used prior to the Internet: flyers requesting volunteers for a study, listings of studies on bulletin boards for students, announcements or listings of studies for psychology students. After reading a description of the study and their rights as anonymous participants, adolescents indicated whether they did not want to proceed with the study or proceeded to the next page indicating their willingness to participate in the study (informed consent). At study design, it was decided to recruit participants until there was useable data for at least 200 participants. The target sample of at least 200 participants was achieved. The target population was adolescents aged 13 to 17 attending school that uses the computer and the Internet during the academic year 2009-2010. In addition, the target population would consist of adolescents willing to complete the survey regarding health and computer use, as participation was voluntary.

They answered items about computer use, Internet use, demographics, health behaviors, parental monitoring, self-control, parents' computer use, friends' computer use among others. At the end of the survey they were free to indicate any comments. Conducting online sur- veys using the Internet has become useful as a tool. ${ }^{15}$ Recruitment through the Internet was thought to be an ideal way to locate adolescents with involvement with computers and the Internet for the current exploratory study. Any duplicated data or incomplete surveys were not included in the analyses.

\section{Sample}

The sample was predominantly girls (63\%), had a mean age of 16.07 $(\mathrm{SD}=1.26)$ years old, and their mean age at first computer use was 7.30 $(\mathrm{SD}=2.29)$ years old. The target group was adolescents between the ages of 13 and 17, which included middle/junior high school, high school and college students. Moreover, they read that they should live in the United States to participate. The sample appeared to be composed of adolescent students using computers making the sample both the target audience and reason for online survey. The majority of participants' specified school, teacher, class or psychology website as means of finding out about the study. This project sample has participated in other studies. One focused on the relationship between alcohol use and computer use (school and excluding school), as well as Internet activities. ${ }^{5}$ The second study concentrated on the association between both health and education factors with measures of computer use (school and excluding school) and electronic game use. ${ }^{16}$ The focus in the current study was on the relationship between factors related to parents, personality characteristics and Internet activities on a newly calculated measure of recreational computer use. The subject matter of the studies differed but each study was part of the parent project. Each represents different aims of the parent project. These studies were described to highlight the lack of similarity between the various studies of the parent project.

\section{Procedure}

Participants were directed to a link to a survey through the recruitment, found the link via an Internet search on their own or from others (websites, teachers, and friends). Once they clicked on the link they were presented with a one-page description of the online anonymous survey and their rights as research participants, which read in part:

You must be between the ages of 13 and 17 to complete the survey. Please help us by respecting this age range.

Completing the survey will take you 10 to 30 minutes. You can finish it when it is convenient for you. There are no risks or discomforts expected from completing the survey. Your survey responses are anonymous and confidential. We will not record any information identifying you. We will not tell anyone about your personal responses. Please do not put your name on the questionnaire.

Your participation is voluntary. That means you do not have to complete the survey if you do not want. You can decide not to finish the survey once you start. You will not get any personal benefit from being in this study, but the research might lead to knowledge that would benefit others.

Adolescents who proceeded to the next page indicated their agreement to participate (informed consent). At the top of each page respondents read: Please provide the following information about yourself. Please be honest. They indicated their responses to a number of items including the following used in the current study: parental monitoring, self-control, age when first used computer (range from 5 to 13 years old), play online games, play violent games, use chat rooms, listen to/download music, educational purposes, my friends use computers for pleasure, and my parents use computers for pleasure. Next, they indicated the usual number of hours per week they spent on i) the computer for schoolwork and ii) the computer excluding schoolwork. From these two measures, a percent of computer use excluding school work/recreational use was computed. Specifically, by adding non-school computer use and school computer use dividing by the combination of these two amounts 
of time multiplied by 100 created a percentage of non-school computer use. This measure served as the dependent variable.

\section{Measures using scales}

Parental monitoring was measured with 6 items with responses of yes/no including: My parents set rules about computers and I must do my homework before using computers or electronic games for fun. These items were specifically developed for this project. Self-Control was measured with items like I am easily distracted from my school work derived from the scale created by Kendall \& Wilcox in which it was found to be reliable ${ }^{17}$ and valid in other work. ${ }^{18}$

\section{Results}

A multiple regression with the computed percentage of non-school computer use per week measure as dependent variable was performed using SPSS Version 18. Preliminary analyses were run to inspect the data and ensure the responses were similar to those of adolescents. The variables entered into the full regression model were: age when first used computer, lack of self-control, parental monitoring, a variety of Internet activities (play online games, play violent games, use chat rooms, listen to or download music, and educational purposes), my friends use computers for pleasure and my parents use computers for pleasure. After this full model was run, variables that were not significant were deleted to create another model. This trimmed model was then tested and only included the significant effects. ${ }^{19}$

The overall trimmed model was highly significant, $F(5,196)=18.55$, $\mathrm{P}<0.001$. Based on the results shown in Table 1, less parental monitoring, younger age at first computer use, listening or downloading music from the Internet more frequently, using the Internet for educational purposes less frequently, and parents use of the computer for pleasure were related to spending a greater percentage of time on non-school computer use.

\section{Discussion}

The present study examined various parental based and social influence and computer-related factors in an attempt to better understand the relationship between these factors and the percentage of time per week spent on the computer excluding schoolwork among adolescents. Specifically, less parental monitoring, younger age at first computer use, listening or downloading music from the Internet more frequently, using the Internet for educational purposes less frequently, and parents' use of the computer for pleasure were related to spending a greater percentage of time on non-school computer use in teens. Scant research with computer-using youth has focused on these measures' association with more computer use in hours per week excluding school work, particularly as a percentage of this type of computer use and computer use related to school work. With this percentage measure of recreational computer use, it was hoped to be a new more creative way of conceptualizing this type of adolescent computer use.

Parental monitoring played an important role through its association with recreational computer use among adolescents. This suggests that parents still maintain an influence over their adolescent children's non-school computer use. In particular like other behaviors, parents can have an impact on decreasing their children's computer use excluding schoolwork. Just as research with other adolescent behaviors, including delinquency, drinking alcohol and drug use, showed links with parental monitoring, ${ }^{7}$ the present study implies a similar relationship with increased non-school computer use in hours per week expressed as a percentage of computer use. For example, parental controls (a type of parental monitoring for the computer and Internet) allow parents to set time limits and keep them within certain websites. ${ }^{9}$ Younger age on the computer was linked with greater recreational (non-school) computer use expressed as a percentage of computer use. Though this was a separate indicator, parents may have well been involved by being too permissive of computer use at a young age. With many activities available on the Internet (including playing online games, playing violent games, using chat rooms, listening to or downloading music, and educational purposes), the present study allowed exploration of the link between these specific Internet activities and percentage of time engaging in non-school computer use. Some of the available possibilities could be risky for adolescents. Though playing violent games and using chat rooms fit this category, they had no relationship with recreational computer use. However, the base rates for these activities were quite low and may require extremely large sample size to adequately address their association with recreational use. Moreover, if the use were measured for a longer time than a week or concentrated on a sample with problematic use or other negative behaviors, then it is possible a relationship may have been discovered. Using the Internet for educational purposes less frequently was related to higher non-school computer use. This suggests that self-education (not for schoolwork) was a reason for being on the Internet that had a protective role in terms of recreational computer use. Apparently, selfeducation and recreation appeared to be more or less mutually exclusive. Parents' use of the computer for pleasure was associated with spending a greater percentage of time on non-school computer use among their adolescent children. Parental monitoring, young age for computer use and parental modeling of using the computer for pleasure were all factors within parents control that were associated with their children's computer use excluding school work. Parental influence can exert a strong role on adolescent computer behavior concerning recreation. Together these findings suggest that to reduce their children's computer use for non-school purposes, parents need to monitor their children's computer use, discourage them from using the

Table 1. Regression model for percent of time on the computer excluding schoolwork per week.

\begin{tabular}{|c|c|c|c|c|c|}
\hline Model & $\begin{array}{l}\text { Uns } \\
\beta\end{array}$ & $\begin{array}{l}\text { cients } \\
\text { Std. Error }\end{array}$ & $\begin{array}{c}\text { Standardized coefficients } \\
\beta\end{array}$ & $t$ & Sig. \\
\hline (Constant) & 81.866 & 7.469 & & 10.961 & 0.000 \\
\hline Parental monitoring & -2.525 & 1.003 & -0.159 & -2.517 & 0.013 \\
\hline Age of first computer use & -1.454 & .562 & -0.155 & -2.585 & 0.010 \\
\hline Listen to or download music from Internet & 3.433 & 1.183 & 0.183 & 2.902 & 0.004 \\
\hline Educational purposes on Internet & -8.442 & 1.237 & -0.428 & -6.827 & 0.000 \\
\hline Parents use computers for pleasure & 3.344 & 1.161 & 0.174 & 2.881 & 0.004 \\
\hline
\end{tabular}

*Dependent variable: adjusted non-school computer time. 
computer too young, and moderate their own computer use for pleasure in the presence of their children to decrease the effect of modeling the behavior. The current study had several strengths and limitations. Relying on self-report measures is a limitation of the study as is the reliance on self-reports from adolescents. However, national surveys of students of sensitive topics such as drug use, including the Monitoring the Future (MTF) survey. ${ }^{20}$ For the MTF anonymous data $\left(8^{\text {th }}\right.$ and $10^{\text {th }}$ grade) and confidential data ( $12^{\text {th }}$ grade) were meant to ensure greater honesty in responding to sensitive information. In the current study, the respondents were in a unique position to adequately describe their computer use. Although it would be interesting to have data from other sources such as parents, due to potentially different styles of parental monitoring and opportunities to be constantly aware of what their children were doing with the computer such data might not be as reliable as from the person engaging in the activity. In addition, the anonymous nature of the study would not have allowed for this possibility unfortunately. This study added more information to a small literature about factors associated with greater computer and created a measure of percentage of computer use in hours per week excluding school use by putting the number of hours of computer use excluding school use as the numerator over the total computer use of computer use for school work and excluding school work. Among its other strengths was including a variety of concurrent predictors related to parental control and Internet activities. A limitation of the study is that the results only apply to adolescents who responded to an online anonymous survey either due to academic reasons or for pure interest, making for potential selection bias. Moreover, these findings do not apply to clinical issues because the study did not concentrate on adolescents identified as having a problem with excessive use of computers. Due to the study's cross-sectional nature, it is limited because no conclusions about causality can be made. The computer use measure was limited to number of hours played per week. One of the participants suggested in the comment section that measurement of number of hours per month would be better. Future research should examine the relationships covered in this study longitudinally. Future longitudinal research must delve into elucidating the relationships found in the present study more fully. Moreover, research needs address parent-child pairs to elucidate the role of parental monitoring and parental role modeling on the children's recreational computer use more explicitly. Parents need to take an interest in how much time their children use computers recreationally. Although some parents engage in parental monitoring and discussing computer use with their children, others may not recognize it as a public health issue with potential health consequences for their children unless limits and guidance are practiced.

Correspondence: Dr. Jennifer A. Epstein, Weill Cornell Medical College, Department of Public Health, Division of Prevention and Health Behavior, 402 East 67th Street, Suite LA-012, New York, NY 10065, USA.

Tel. +1.646 .9628056 - Fax: +1.646 .9620284 .

E-mail: jepstein@med.cornell.edu

Key words: adolescents, recreational computer use, advice for parents, parental monitoring.

Acknowledgments: this research was supported by a grant from the National

Science Foundation (NSF 0960391) to Dr. Epstein.

Conflict of interest: the authors declare no conflicts of interest.

Received for publication: 10 November 2011.

Accepted for publication: 1 February 2012.

(C) Copyright J.A. Epstein, 2012

Licensee PAGEPress, Italy

Journal of Public Health Research 2012; 1:e13

doi:10.4081/jphr.2012.e13

This work is licensed under a Creative Commons Attribution NonCommercial 3.0 License (CC BY-NC 3.0)

\section{References}

1. Watkins SC. The young and the digital: what the migration to social network sites, games, and anytime, anywhere media means for our future. 2009, Beacon Press, Boston, USA.

2. Lemmens JS, Valkenburg PM, Peter J. Development and validation of a game addiction scale for adolescents. Media Psychol 2009;12:77-95.

3. Ng BD, Wiemer-Hastings P. Addiction to the internet and online gaming. Cyberpsychol Behav 2005;8:110-3.

4. Kuss DJ, Griffiths MD. Online social networking and addiction-a review of the psychological literature. Int J Environ Res Public Health 2011;8:3528-52.

5. Epstein JA. Adolescent computer use and alcohol use: What are the role of quantity and content? Addict Behav 2011;36:520-2.

6. CASA. National survey of American attitudes on substance abuse XVI: teen and parents. 2011. Available from: http//www.casacolumbia.org/ templates/publications_reports.aspx

7. Stattin H, Kerr M, Tilton-Weaver L. Parental monitoring: A critical examination of the research. In: V. Guilamo-Ramos, J. Jaccard and P. Dittus (eds.) Parental monitoring of adolescents in current perspectives for researchers and practitioners. 2010, Columbia University Press, New York, USA.

8. Biglan A. Selection by consequences: One unifying principle for a transdisciplinary science of prevention. Prev Sci 2003;4:213-32.

9. Mattos SN. Online and Offline Parental Control. 2010, CreatSpace Publ., Seattle, USA.

10. Duckworth A. The significance of self-control. PNAS 2011;108: 263940.

11. Englehardt CR, Bartholow BD, Kerr GT, Bushman BJ. This is your brain on violent video games: Neural desensitization to violence predicts increased aggression following violent video game exposure. J Exp Soc Psychol 2011;47:1033-36.

12. Dowell EB, Burgess AW, Flores JRJD. Online social networking patterns among adolescents, young adults and sexual offenders. Amer J Nurs 2011;111:28-36.

13. Bandura A. Social foundations of thought and action. 1986, PrenticeHall, Englewood Cliffs, USA.

14. Hawkins JD, Catalano RF, Miller JY. Risk and protective factors for alcohol and other drug problems in adolescence and early adulthood: Implications for substance abuse prevention. Psychol Bull 1992;112: 64-105.

15. Van Selm M, Jankowski NW. Conducting online surveys. Qual Quant 2006;40:435-45.

16. Epstein JA. Factors related to adolescent computer use and electronic game use. ISRN Public Health, vol. 2012, Article ID 795868.

17. Kendall PC, Wilcox LE. Self-control in children: development of a rating scale. J Consult Clin Psychol 1979;47:1020-9.

18. Rohrbeck CA, Azar ST, Wagner PE. Child self-control rating scale: Validation of a child self-report measure. J Clin Child Psychol 1991;20: 179-83.

19. Cohen J, Cohen P, West SG, Aiken LS. Applied multiple regression/correlation analysis for the behavioral analysis. 3rd edition 2003, Lawrence Erlbaum Publ., Mahwah, USA.

20. Johnston LD, O'Malley PM, Bachman JG, Schulenberg JE. Monitoring the future national survey results on drug use, 1975-2010. Volume I: Secondary school students. 2011, Institute for Social Research, University of Michigan, Ann Arbor, USA. 